\title{
Produção e efeitos do uso de hidrogel natural na cultura do alface
}

\author{
Luma Rayane de Lima Nunes ${ }^{1 *}$, Cleilson do Nascimento Uchôa ${ }^{2}$, Renata Chastinet Braga ${ }^{2}$
}

\begin{abstract}
RESUMO: O referido experimento foi desenvolvido com o objetivo de avaliar a influência dos polímeros retentores de água naturais produzidos a partir de polissacarídeos extraídos de sementes de Adenanthera pavonina L. na germinação e vigor de sementes de alface da cultivar americana. Inicialmente foi realizada a produção do hidrogel, para em seguida proceder com a condução dos testes. Foram utilizadas sementes de alface do genótipo crespa Grand Rapids. Conduzido em delineamento inteiramente casualizado, com os resultados obtidos, analisados a significância de 5\%, com o auxílio do programa estatístico SISVAR®. Para as variáveis: germinação (\%), primeira contagem (\%) e comprimento da plântula $(\mathrm{cm})$, os tratamentos consistiam em diferentes dosagens do polímero: T1 (testemunha) - volume de água equivalente a 2,5 vezes o seu peso; T2 - 4,0 gramas do polímero; T3 - 8,0 gramas e T4 - 12,0 gramas. Para emergência (\%) e massa fresca das plântulas (g), foram utilizadas quatro dosagens do hidrogel $(0 ; 1,0 ; 2,0 ; 3,0 \mathrm{~g}$ por $600 \mathrm{~g}$ de composto $^{-1}$ ). A utilização do hidrogel natural é benéfica à produção de mudas de alface, por armazenar um elevado volume de água, disponibilizando conforme a necessidade das sementes. As maiores dosagens testadas, proporcionaram as maiores médias obtidas às variáveis analisadas.
\end{abstract}

Palavras-chave: disponibilidade hídrica, germinação, vigor, Lactuca sativa $\mathrm{L}$

\section{Production and effects of the use of natural hydrogel on lettuce}

\begin{abstract}
This experiment was carried out with the objective of evaluating the influence of natural water retention polymers produced from polysaccharides extracted from Adenanthera pavonina L. seeds on the germination and vigor of lettuce seeds of the American cultivar. Initially, the production of the hydrogel was performed, and then proceeded with the conduction of the tests. Beans seeds of the Grand Rapids crespa genotype were used. It was conducted in a completely randomized design, with the results obtained, analyzed the significance of 5\%, with the aid of the statistical program SISVAR $®$. For the variables: germination $(\%)$, first count $(\%)$ and seedling length $(\mathrm{cm})$, the treatments consisted of different dosages of the polymer: T1 (control) - water volume equivalent to 2.5 times its weight; T2 - 4.0 grams of the polymer; T3 - 8.0 grams and T4 -12.0 grams. For emergence $(\%)$ and fresh seedling mass $(\mathrm{g})$, four hydrogel dosages $\left(0,1.0,2.0,3.0 \mathrm{~g}\right.$ per $600 \mathrm{~g}_{\text {of }}$ compound $\left.{ }^{-1}\right)$ were used. The use of the natural hydrogel is beneficial to the production of lettuce seedlings, by storing a high volume of water, making available according to the need of the seeds. The higher dosages tested provided the highest averages obtained for the analyzed variables.
\end{abstract}

Keywords: water availability, germination, vigor, Lactuca sativa $\mathrm{L}$

\section{INTRODUÇÃO}

No desenvolvimento de uma planta, o primeiro evento fisiológico que ocorre é a germinação das sementes, que posteriormente induz ao crescimento do embrião e à emergência das plântulas. O processo germinativo é constituído por uma sequência de eventos físicos, bioquímicos e fisiológicos, que são influenciados por vários fatores, que podem atuar isolados ou em interação, dentre eles: disponibilidade hídrica, temperatura e oxigênio (MARCOS FILHO, 2015).

Para que desencadei a germinação, a semente necessita absorver uma quantidade mínima de água que é variável de acordo com o tipo de semente (FLOSS, 2011). A utilização de técnicas que acelerem e uniformizem a germinação das sementes poderá propiciar grandes benefícios aos produtores de mudas (FESSEL et al., 2001).

A alface (Lactuca sativa L.) consiste na folhosa mais consumida na forma in natura, sendo considerada como uma das hortaliças mais importantes para dieta da população, tanto pelo sabor, o baixo custo e a qualidade nutritiva, por ser fonte de vitaminas, sais minerais e fibras (SANTI et al., 2010). Em virtude dessa crescente demanda, fazse necessário à ampliação das áreas destinadas ao seu plantio, mas, às condições climáticas se apresentam como fator limitante (DENG; SONG, 2012). Essa cultura não difere das demais, por se apresentar exigente em água, necessitando de um manejo adequado de irrigação, que além de suprir as necessidades hídricas das plantas, mas, também minimize problemas com doenças, lixiviação de

Recebido em 31/07/2018; Aceito para publicação em 01/11/2019

${ }^{1}$ Universidade Federal do Ceará

${ }^{2}$ Instituto Federal do Ceará

*E-mail: lumanunes20@ hotmail.com 
nutrientes e gastos desnecessários com água (KOETZ et al., 2006). Vários estudos que consistem em tratamentos pré-germinativos, tais como, o condicionamento osmótico tem sido realizado com intuito de melhorar a porcentagem de germinação e a expressão de vigor das sementes de alface (MENEZES et al., 2006).

A adoção de polímeros retentores de água surgem como uma opção ao condicionamento osmótico das sementes, uma vez que possuem a capacidade de absorver grandes volumes de água, de 150 a 400 vezes a sua massa seca (VALE et al., 2006).

A absorção de água pelo hidrogel diminui o índice de percolação da água para as camadas mais profundas e distantes das raízes, mantendo a água armazenada próximo a elas, impedindo a perda de umidade para o ambiente, liberando água de maneira gradativa para a planta. Porém, o uso imoderado de hidrogel pode ocasionar na diminuição da aeração do substrato, vindo ser capaz de causar apodrecimento das raízes, por reter água excessivamente (VICENTE et al., 2015).

Esses retentores podem ser de origem natural (derivados de carboidratos) ou sintéticos, como a propenamida (denominados de poliacrilamida ou PAM) e os co-polímeros, como a propenamidapropenoato (conhecidos como poliacrilamidaacrilato ou PAA), usados como floculantes em fraldas e outros artigos sanitários, e para depósitos de líquidos químicos residuais (VALE et al., 2006). Mas, por não serem biodegradáveis, estes geram resíduos no solo provocando a salinização do meio (MENDONÇA et al., 2013).

Estudos sobre o papel da água na germinação das sementes são essenciais para entender o processo germinativo. Em vista dessa consideração, objetivou-se avaliar a influência dos polímeros retentores de água naturais produzidos a partir de sementes de Adenanthera pavonina L. na germinação e vigor de sementes de alface da cultivar americana.

\section{MATERIAL E MÉTODOS}

A condução do experimento foi realizada em duas partes: a fabricação do hidrogel natural desenvolvida no laboratório de Química Geral, e a avaliação da germinação, no laboratório de Biologia ambos localizados no Instituto Federal do Ceará, campus de Limoeiro do Norte, e a avaliação do vigor de sementes de alface a partir da utilização do hidrogel desenvolvidos na Unidade de Ensino, Pesquisa e Extensão do IFCE localizada na Chapada do Apodi, a $05^{\circ} 10^{\prime} 53^{\prime \prime} \mathrm{S}$ e $38^{\circ} 00^{\prime} 43^{\prime \prime}$ W e $146 \mathrm{~m}$ de altitude.
Para a produção do hidrogel foram usadas sementes maduras de Adenanthera pavonina L. coletadas de árvores situada no IFCE Campus de Limoeiro do Norte, durante os meses de agosto a novembro de 2016. Inicialmente, procedeu-se com a extração do polissacarídeo, que consistia no cozimento de 70 gramas de sementes por duas horas, retirados o endosperma e colocados com água no liquidificador durante cinco minutos para formar um líquido viscoso e homogêneo, ficando em repouso por 12 horas. Para cada grama de semente cozida, acrescentou-se $10 \mathrm{~mL}$ de água destilada.

No dia seguinte esta solução foi centrifugada a 3.000 RPM durante 20 minutos; o sobrenadante obtido foi precipitado com álcool etílico a 96\% (1:3 v/v) e deixado em repouso por 12 horas. Decorrido esse tempo, o precipitado foi filtrado em bomba a vácuo com o funil de placa porosa $n^{\circ} 2$. O material seco foi colocado em acetona para que fosse retirado todo o excesso de água ainda presente, deixando-o em repouso por 12 horas. No dia seguinte, procedeuse novamente a secagem na bomba a vácuo, para que fosse realizada a retirada do excesso de acetona, e posteriormente, procedeu com a secagem do material utilizando secador de cabelo.

A reticulação do polissacarídeo foi obtida por meio de reação cruzada com epicloridrina em meio básico, em que, a preparação consistia em: $0,5 \mathrm{~g}$ de polissacarídeo + 1,5 mL de $\mathrm{NaOH} 3 \mathrm{Mol}+0,15 \mathrm{~mL}$ de epicloridrina P.A. Depois de homogeinizada, a mistura foi levada a estufa de circulação de ar forçada a $40^{\circ} \mathrm{C}$ durante 24 horas, e em seguida, a temperatura foi elevada a $75^{\circ} \mathrm{C}$ e passados mais 12 horas. Decorrido esse tempo, o material foi exaustivamente lavado com água destilada (atingir pH 6-7) e posteriormente passado por uma peneira para determinar o tamanho dos grânulos do gel. A amostra foi levada ao liofilizador para a remoção de todo o excesso de água.

Antes de avaliar os efeitos da aplicação do hidrogel na germinação e vigor das sementes de alface, procedeu-se uma caracterização físicoquímica do mesmo, conforme os resultados estão representados na tabela 1 .

Tabela 1 - Características Físico-químicas do polímero retentor de água utilizado.

$\begin{array}{ll}\text { Condutividade elétrica }\left(\mathrm{dS} . \mathrm{m}^{-1}\right) & 0,0235 \\ \mathrm{pH}(\mathrm{em} \text { água }) & 8,96 \\ \text { Umidade máxima } & 87,5 \\ \mathrm{Ca}^{2+}\left(\mathrm{g} \cdot \mathrm{kg}^{-1}\right) & 8,2 \\ \mathrm{Mg}{ }^{2+}\left(\mathrm{g} \cdot \mathrm{kg}^{-1}\right) & 2,2 \\ \mathrm{~S}\left(\mathrm{~g} \cdot \mathrm{kg}^{-1}\right) & 0,1 \\ \mathrm{Na}\left(\mathrm{g} \cdot \mathrm{kg}^{-1}\right) & 1,281 \\ \mathrm{Fe}\left(\mathrm{mg} \cdot \mathrm{kg}^{-1}\right) & 62,5\end{array}$


Para a condução dos testes foram utilizadas sementes de alface do genótipo crespa Grand Rapids, as quais foram submetidas à determinação do teor de água conforme descrito por Brasil (2009).

$\mathrm{Na}$ condução do teste de germinação foram utilizadas quatro amostras de 50 sementes, as quais foram semeadas sobre duas folhas de papel do tipo Germitest ${ }^{\circledR}$ em caixas de plástico do tipo Gerbox ${ }^{\circledR}$ e acondicionadas em BOD na condição controlada de temperatura para $25^{\circ} \mathrm{C}$ e fotoperíodo de 12 horas. Para avaliação do vigor, no quarto dia da instalação do teste realizou-se a primeira contagem de germinação. No sétimo dia, observou-se a germinação total e determinou-se a percentagem de plântulas normais em relação ao número de sementes empregadas na amostra. Utilizou-se como critério de classificação de plântulas normais as definições estabelecidas por Brasil (2009). A análise do crescimento das plântulas foi determinada após sete dias de instalação do teste de germinação, selecionando 10 plântulas por amostra para proceder com as mensurações, que foram realizadas com o auxílio de régua graduada $\mathrm{em} \mathrm{cm}$.

Os tratamentos adotados consistiam em diferentes dosagens do polímero, sendo esse aplicado no momento de umedecimento do papel Germitest ${ }^{\circledR}$, ou seja, em vez de se acrescentar água na proporção de 2,5 vezes o peso do papel, foi adotado uma camada de polímero, sendo este o responsável pelo fornecimento de água às sementes no momento da germinação. Os tratamentos consistiam em: T1 (testemunha) - volume de água equivalente a 2,5 vezes o seu peso; $\mathrm{T} 2-4,0$ gramas do polímero; T3 - 8,0 gramas do polímero e T4 -
12,0 gramas do polímero. Vale destacar que esse peso do polímero era constituído por $87 \%$ de água.

Já o teste de emergência foi realizado em condições de ambiente protegido situado na área experimental da UEPE. Foram utilizadas bandejas de polietileno expandido com 200 células individuais, contendo composto orgânico como substrato. As bandejas receberam irrigações diárias, sendo a mesma lâmina aplicada a todos os tratamentos. Utilizou-se o delineamento experimental inteiramente casualizado, testando quatro concentrações de hidrogel usada $(0 ; 1,0 ; 2,0$; $3,0 \mathrm{~g}$ por $600 \mathrm{~g}$ de composto ${ }^{-1}$ ) com quatro repetições de 50 sementes por repetição. A avaliação da emergência das plântulas foi efetuada aos 10 dias após a semeadura, mediante a contagem de plântulas emergidas (PE), das quais foram selecionadas 20 para proceder com a avaliação da massa fresca das plântulas (MFP).

Os resultados obtidos em ambos os testes foram submetidos ao teste de normalidade, para em seguida proceder com à comparação de médias pelo teste de Tukey e a análise de regressão, ambas a significância de 5\%. Utilizou-se o programa estatístico SISVAR® (FERREIRA, 2011).

\section{RESULTADOS E DISCUSSÃO}

De acordo com os resultados obtidos na análise estatística (Tabela 2), observou-se diferenças significativas entre as variáveis analisadas e as dosagens de hidrogel.

Tabela 2. Resumo da análise de variância para germinação (G \%), primeira contagem de germinação (PC \%), plântulas emergidas (PE \%), comprimento das plântulas (COMP $-\mathrm{cm}$ ) e massa fresca da plântula (mg.plântula $\left.{ }^{-1}\right)$ de alface produzidas em diferentes dosagens de hidrogel, Limoeiro do Norte, 2016.

\begin{tabular}{|c|c|c|c|c|c|}
\hline \multirow[b]{2}{*}{ F.V. } & \multicolumn{5}{|c|}{ Quadrado médio das variáveis } \\
\hline & $\mathrm{G}(\%)$ & $\mathrm{PC}(\%)$ & PE $(\%)$ & COMP & MFP \\
\hline Tratamento & $803,00 * *$ & $580,67 * *$ & $416,67 * *$ & $1,24 * *$ & $0,0063 * *$ \\
\hline Média & 78,25 & 75,50 & 77,50 & 1,75 & 49,87 \\
\hline C.V. $(\%)$ & 2,29 & 3,48 & 3,99 & 2,31 & 3,82 \\
\hline
\end{tabular}

** significativo a $1 \%$, *significativo a $5 \%$ de probabilidade e ns - não significativo.

Para a variável germinação, notou-se um aumento linear de 69,20 unidades na média conforme se elevaram as dosagens de hidrogel utilizadas (Figura 1). Esse acréscimo deve-se a maior disponibilidade de água durante o processo germinativo, em que, quanto maior a dosagem empregada, maiores eram os volumes ofertados, resultando em: $6,25 \mathrm{ml}$ (2,5 vezes o peso do papel); $3,48 \mathrm{ml}$ (1,4 vezes o peso); $6,96 \mathrm{ml}$ (2,8 vezes o peso) e $10,44 \mathrm{ml}$ (4,0 vezes o peso), tratamentos 1 , 2,3 e 4 , respectivamente. A água é fundamental ao metabolismo celular da germinação, por interferir na atividade enzimática, na solubilização e transporte de fotoassimilados, atuando como reagente na digestão das reservas da semente (MARCOS FILHO, 2015). 


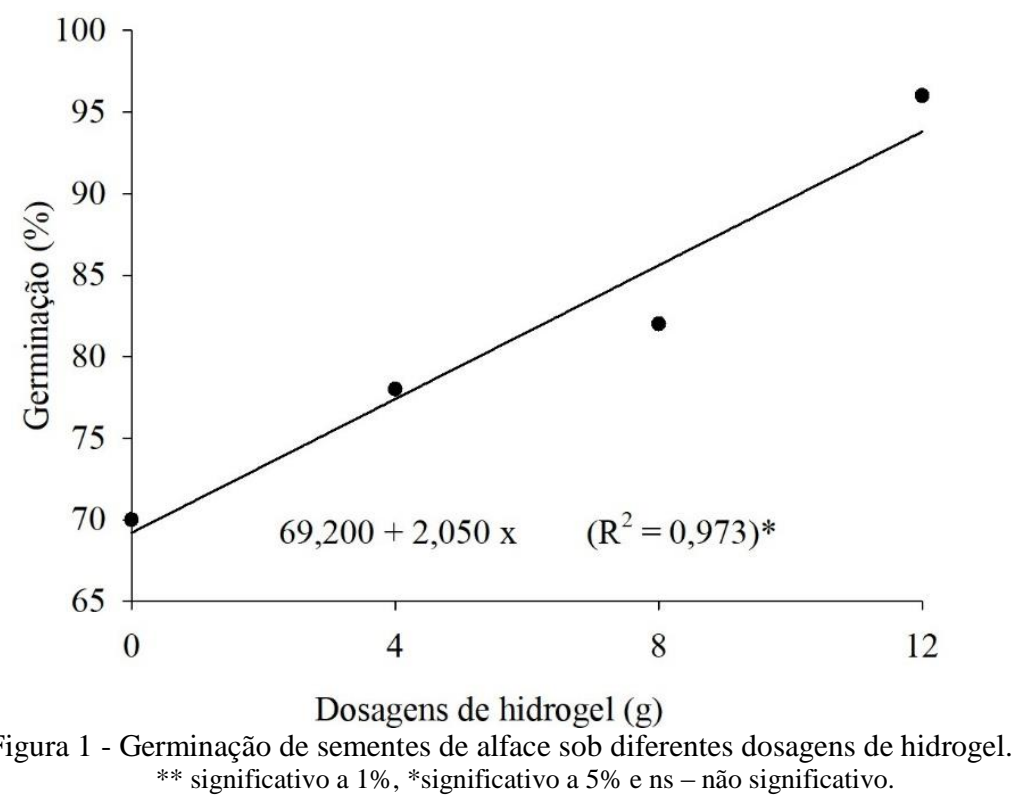

Para o fato de ser ter obtido maior taxa de germinação quando o substrato foi umedecido com aproximadamente 4,0 vezes o peso do papel seco (tratamento 4), outros autores encontraram resultados que corroboram aos obtidos nesse experimento: Silva et al. (2008), onde ao analisar diferentes teores de umidade $(2,0 ; 2,5 ; 3,0$ e 3,5 vezes o peso do papel $(\mathrm{g})$ ), no teste de germinação de sementes de pinhão-manso (Jatropha curcas L.), encontrou o melhor desempenho quando o substrato foi umedecido com volumes de água (ml) equivalentes a 3,0 e 3,5 vezes o peso do papel mataborrão, ocorrendo a redução da germinação e vigor quando o substrato foi umedecido com valores inferiores a estes. Guedes et al. (2010), com sementes de Amburana cearensis (All.) obteve o maior percentual de germinação quando utilizou o volume de água correspondente a 3,25 vezes o peso do substrato seco.

No entanto, outros pesquisadores defendem resultados que se contrapõem aos acima citados, que ao se elevar os teores de água disponível às sementes nos testes de germinação, percebe-se uma influência desfavorável apresentando uma redução na quantidade de plântulas normais, o que pode ser justificado por Marcos-Filho (2015), onde o excesso de água restringe a disponibilidade de oxigênio para as sementes acarretando efeitos semelhantes aos do estresse hídrico. Além de contribuir para a proliferação de patógenos (PACHECO et al., 2006). Dentre os autores que associaram a redução no número de sementes germinadas ao elevado teor de umidade do substrato, pode-se mencionar: Azeredo et al. (2010) trabalhando com sementes de repolho indicam que os teores de água para umedecer o substrato deve se encontrar na faixa de 1,5 a 2,5 vezes a massa do papel, enquanto os teores acima de 3,0 vezes prejudicam à germinação.

Um fato que merece atenção é a metodologia pela qual a água é disponibilizada às sementes nos testes de germinação, que como já comentado, quando se eleva os volumes fornecidos, há uma tendência à ocorrência de prejuízos. Realidade completamente inversa à obtida nesse experimento, onde, apesar de se ter trabalhado com sementes de alface, observou-se que conforme se aumentava os teores de umidade, maior eram as porcentagens apresentadas, resultando quase que na totalidade da germinação. Essa elevada taxa pode ser atribuída ao uso do hidrogel, que de acordo com Bernardi et al. (2012), a comercialização do polímero retentor de água vem sendo incentivada com a justificativa de permitir maior retenção de água podendo ser lentamente liberados para as plantas em função dos ciclos absorção - liberação.

$\mathrm{O}$ teste de primeira contagem apresentou resultados semelhantes aos do teste de germinação, demonstrando que conforme se elevavam as dosagens de hidrogel utilizadas, maiores foram as médias obtidas. Para essa variável, a equação de regressão se ajustou ao modelo linear (Figura 2). 


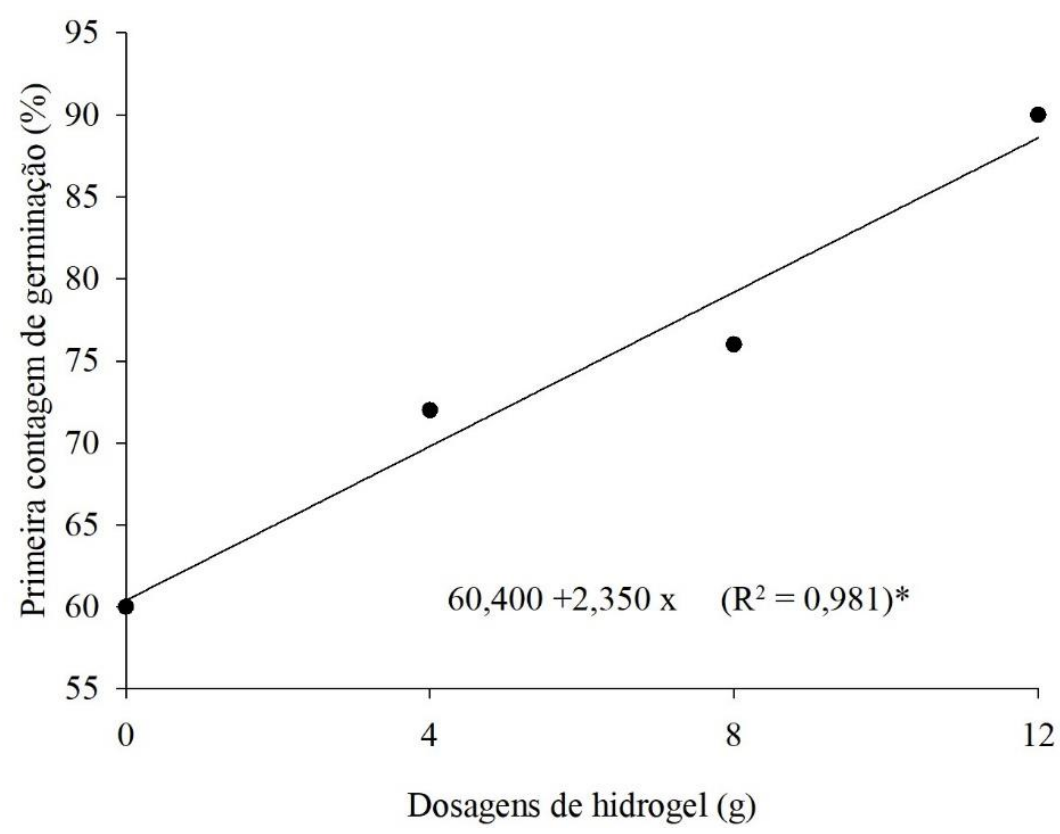

Figura 2 - Primeira contagem de germinação de sementes de alface sob diferentes dosagens de hidrogel. ** significativo a $1 \%$, *significativo a $5 \%$ e ns - não significativo.

A partir dos resultados obtidos para aplicação do hidrogel no crescimento das plântulas de alface, notou-se uma resposta positiva para essa variável conforme se elevaram as dosagens de polímero

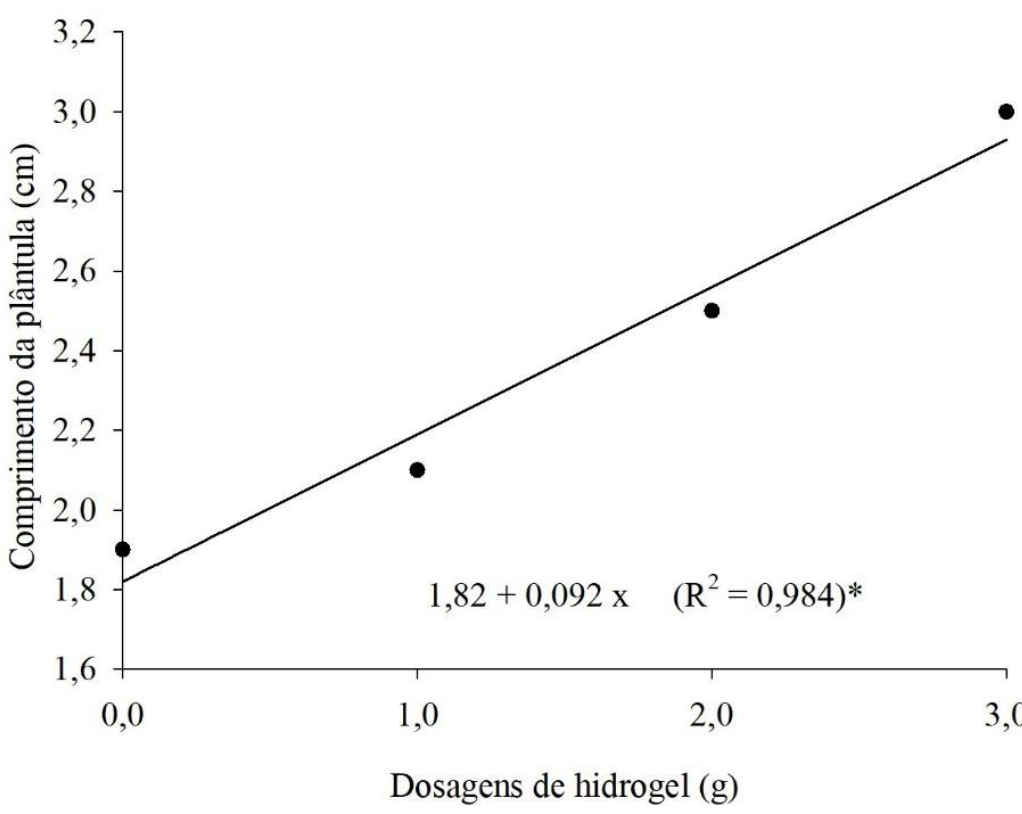

Figura 3 - Comprimento das plântulas de alface sob diferentes dosagens de hidrogel ** significativo a $1 \%$, *significativo a $5 \%$ e ns - não significativo. retentor utilizadas (Figura 3), com ajuste polinomial linear $(\mathrm{p}<0,05)$ sendo a dose de 4 gramas a que resultou em maior incremento na altura $(3,02 \mathrm{~cm})$.
Ao avaliar o crescimento das plântulas, percebeu-se que as dosagens que proporcionou os teores de umidade do substrato mais baixas, foram obtidas as menores médias, como no caso, os tratamentos 1 e 2, apresentando plântulas raquíticas e comprimento inferior a 2 centímetros. A principal causa para esses resultados deve-se ao estresse hídrico que foi aplicado a esses tratamentos, uma vez que a água atua como fator limitante na sobrevivência e no crescimento inicial das plantas, afetando diretamente o alongamento celular em virtude da redução da turgescência e controlando a abertura dos estômatos e consequentemente, a produtividade (TAIZ et al., 2017).

Corroborando a esses resultados, menciona-se Gordin et al. (2015), ao afirmarem que o 
comprimento médio da parte aérea e das raízes de níger (Guizotia abyssinica Cass) apresentaram redução em função do decréscimo da disponibilidade hídrica do substrato, com os seguintes potenciais osmóticos: 0,0 Mpa (controle); 0,1 Mpa; -0,2 Mpa; -0,3 Mpa; e -0,4 Mpa. Dourado et al. (2014) analisando o crescimento do alface, observaram redução na altura das plantas quando submetidas a reposição de 50 e $75 \%$ da água do solo, no entanto, ao nível de $150 \%$ de reposição foi atingida a altura máxima de 17 centímetros. Ao trabalhar com berinjela submetida à diferentes tensões de água no solo $(15,30,45,60$ e $80 \mathrm{kPa})$, Biliblio et al. (2010) observaram que a altura das plantas apresentou resposta linear em relação às tensões as quais foram submetidas, indicando que, para cada variação unitária crescente da tensão, deuse uma redução de $0,45 \mathrm{~cm}$ no crescimento das plantas.
De acordo com Duarte (2012), a deficiência hídrica influencia todos os aspectos do crescimento das plantas, provocando mudanças em sua anatomia, fisiológica e bioquímica. Em que, a divisão e expansão celular são os primeiros processos a serem afetados, sendo retardados ou até mesmo, interrompidos. Dessa forma, o crescimento das folhas e caules diminui bem antes do estresse hídrico tornar-se severo a ponto de causar o fechamento dos estômatos e uma diminuição na fotossíntese.

Para o teste de emergência realizado em campo, foi encontrado diferença significativa entre todos os tratamentos, onde repetiu-se os mesmos resultados obtidos no teste de germinação, apresentando um crescimento proporcional ao aumento das dosagens de hidrogel adotada (Figura 4).

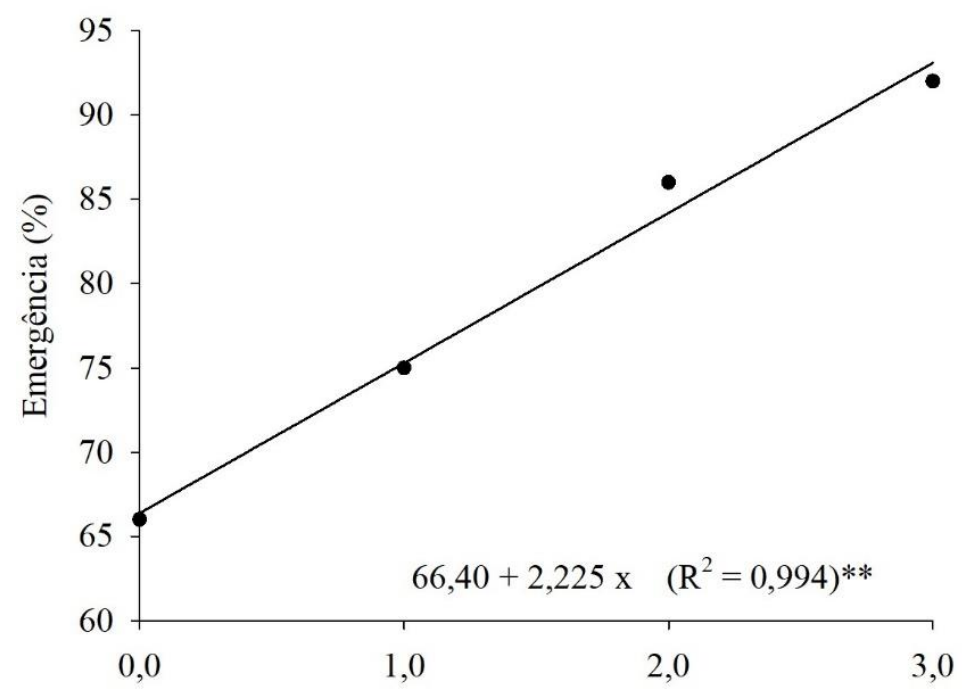

Dosagens de hidrogel $(\mathrm{g})$ Figura 4 - Teste de emergência das plântulas de alface sob diferentes dosagens de hidrogel.
$* *$ significativo a $1 \%$, *significativo a 5\% e ns - não significativo.

Para a variável plântulas emergidas (PE) notouse que a aplicação de $3,0 \mathrm{~g}$ para $600 \mathrm{~g}$ de composto orgânico $^{-1}$ (tratamento 4) mostrou-se superior quando comparado aos demais tratamentos, comprovando a eficácia quanto ao armazenamento de água.

Essa capacidade é de suma importância para a germinação das sementes de alface, pois como se sabe, elas apresentam alta sensibilidade às variações ambientais capazes de ocasionar problemas na germinação (EIRA; MARCOS FILHO, 1990). Como solução a esse problema, vários autores recomendam o condicionamento osmótico, onde para as condições em que o experimento foi desenvolvido a aplicação do polímero junto ao substrato mostrou-se favorável.
De acordo com Marques et al. (2013), o hidrogel também aumenta a porosidade total, não afetando a disponibilidade hídrica e proporciona aumento do volume de água de reserva do substrato, favorecendo o melhor desempenho da parte aérea das plantas.

Já a variável massa fresca das plântulas (MFP) notou-se que conforme foi se aumentando a dosagem do polímero condicionador de solo, houve um aumento de forma linear para o peso, onde os tratamentos que consistiam em 2,0 g e 3,0 g para $600 \mathrm{~g}$ de composto orgânico ${ }^{-1}$ (tratamentos 3 e 4 , respectivamente), não diferiram estatisticamente entre si, contudo mostraram-se superiores aos demais tratamentos (Figura 5). Esses dados comprovam a grande importância que a água exerce 
no desenvolvimento das plantas e que sua deficiência pode vir comprometê-lo severamente.

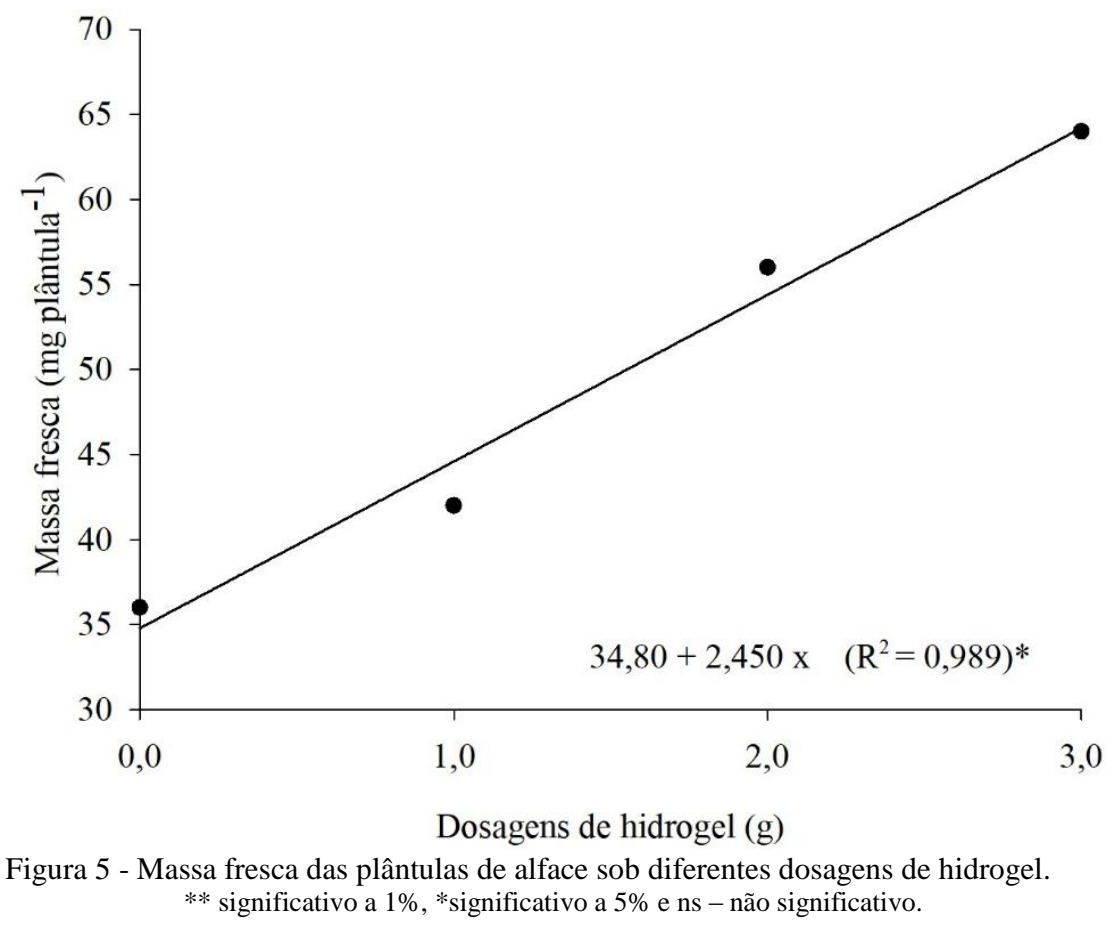

Inúmeras pesquisas já foram realizadas na tentativa de comprovar a influência do uso do polímero na produção de diversas culturas, visando não só a produção, mas, também a eficiência no uso da irrigação, dentre as quais: Albuquerque Filho et al. (2009), concluíram que o rendimento de massa verde, massa seca e o número de plantas de coentro, aumentaram linearmente com a elevação das dosagens do polímero quando se adotou uma lâmina mínima de irrigação (60\% ETo); já na adoção de uma lâmina máxima (120\% ETo), as estimativas das características vegetativas foram maximizadas com doses ideais na faixa de 6 a $11 \mathrm{dg} \mathrm{kg}^{-1}$ e o emprego da dose máxima $16 \mathrm{dg} \mathrm{kg}^{-1}$ proporcionou queda em relação à testemunha devido ao excesso de água. Azevedo et al. (2002), afirmaram que a altura e o peso seco de plantas de cafeeiro aumentaram com a adição de polímero superabsorvente no substrato de transplantio, o que também permitiu o aumento do intervalo entre as irrigações, sem comprometer o crescimento.

\section{CONCLUSÃO}

A partir dos resultados obtidos nos testes de germinação e vigor, conclui-se que a utilização do hidrogel natural é benéfica à produção de mudas de alface, por armazenar um elevado volume de água, disponibilizando conforme a necessidade das sementes. As maiores dosagens do hidrogel testadas, proporcionaram as maiores médias obtidas às variáveis analisadas.

\section{AGRADECIMENTOS}

Ao apoio dado pelo Instituto Federal do Ceará, campus de Limoeiro do Norte, pela disponibilidade dos laboratórios necessários a realização do experimento.

\section{REFERÊNCIAS}

ALBUQUERQUE FILHO, J. A. C.; LIMA, V. L. A.; MENEZES, D.; AZEVEDO, C. A. V.; DANTAS NETO, J.; SILVA JÚNIOR, J. G. Características vegetativas do coentro submetido a doses do polímero hidroabsorvente e lâminas de irrigação. Revista Brasileira de Engenharia Agrícola e Ambiental, Campina Grande, v. 13, n. 6, p. 671-679, 2009.

AZEREDO, G. A.; SILVA, B. M. S.; SADER, R.; MATOS, V. P. Umedecimento e substratos para germinação de sementes de Repolho. Pesquisa Agropecuária Tropical, Goiânia, v. 40, n. 1, p. 77-82, 2010.

AZEVEDO, T. L. de F.; BERTONHA, A.; GONÇALVES, A. C. A.; FREITAS, P. S. L. de; REZENDE, R.; FRIZZONE, J. A. Níveis de polímero superabsorvente, frequências de irrigação e crescimento de mudas de café. Acta Scientiarum, Maringá, v. 24, n. 5, p. 1239-1243, 2002.

BERNADI, M. R.; JÚNIOR, M. S.; DANIEL, O.; VITORINO, A. C. T. Crescimento de mudas de Corymbia citriodora em função do uso de hidrogel e adubação nitrogenada. Revista Cerne, Lavras, v. 18, n. 1, p. 67-74. 2012. 
BILIBIO, C.; CARVAlHO, J. A.; MARTINS, M. A.; REZENDE, F. C.; FREITAS, E. A.; GOMES, L. A. A. Desenvolvimento vegetativo e produtivo da berinjela submetida a diferentes tensões de água no solo. Revista Brasileira de Engenharia Agrícola e Ambiental, Campina Grande, v. 14, n. 7, p.730-735, 2010.

BRASIL. Ministério da Agricultura, Pecuária e Abastecimento. Regras para análise de sementes. Brasília: Mapa/ACS, 2009. 399 p.

DENG, Z.; SONG, S. Sodium nitroprusside, ferricyanide, nitrite and nitrate decrease the termo-domancy of lettuce seed germination in the a nitric oxide dependente manner in light. South African Journal of Botany, v. 78, p: 139$146,2012$.

DOURADO, L. G. A.; KOETZ, M.; BONFIM-SILVA, E. M.; SILVA, T. J. A.; GUIMARÃES, S. L. Reposição de água na cultura da alface lisa com a utilização do irrigas em ambiente protegido. Enciclopédia Biosfera, Goiânia, v. 10, n. 18, p: 2633-2646, 2014.

DUARTE, A. L. M. Efeito da água sobre o crescimento e o valor nutritivo das plantas forrageiras. Pesquisa \& Tecnologia, v. 9, n. 2, 2012.

EIRA, M. T.; MARCOS FILHO, J. Condicionamento fisiológico de sementes de alface: efeitos sobre a germinação. Revista Brasileira de Sementes, Brasília, v. 12, n. 1, p. 9-27, 1990.

FESSEL, S. A.; VIEIRA, R. D.; RODRIGUES, T. J. D.; FAGIOLI, M.; PAULA, R. C. Eficiência do condicionamento osmótico em sementes de alface. Revista Brasileira de Sementes, v. 23, n. 1, p.128-133, 2001 .

FERREIRA, D. F. Sisvar: A computer statistical analysis system. Ciência e Agrotecnologia, Lavras, v. 35, n. 6, p. 1039-1042, 2011.

FLOSS, E. L. Fisiologia das plantas cultivadas: o estudo que está por trás do que se vê. 5. ed., Paso Fundo: Universidade de Passo Fundo, 2011. 733p.

GUEDES, R. S.; ALVES, E. U.; GONÇALVES, E. P.; VIANA, J. S.; FRANÇA, P. R. C.; LIMA, C. R. Umedecimento do substrato e temperatura na germinação e vigor de sementes de Amburana cearenses (All.) A.C. Smith. Revista Brasileira de Sementes, Londrina, v. 32, n. 3, p: 116-122, 2010.

GORDIN, C. R. B.; SCALON, S. P. Q.; MASETTO, T. E. Disponibilidade hídrica do substrato e teor de água da semente na germinação de niger. Pesquisa Agropecuária Tropical, Goiânia, v. 45, n. 3, p. 312-318, 2015.

KOETZ, M.; COELHO, G.; COSTA, C. C. C.; LIMA, E. P; SOUZA, R. J. Efeito De doses de potássio e da frequência de irrigação na produção alface-americana em ambiente protegido. Engenharia Agrícola, Jaboticabal, v. 26, n. 3, p. 730-737, 2006.

MARCOS FILHO, J. Fisiologia de sementes de plantas cultivadas. 2. ed., Londrina: ABRATES, 2015. 660p.

MARQUES, T. A.; RAMPAZO, E. M; MARQUES, P. A. A. Oxidative enzymes activity in sugarcane juice as a function of the planting system. Food Science and Technology, Campinas, v. 33, n. 1, p: 146-150, 2013.

MENDONÇA, T. G.; URBANO, V. R.; PERES, J. G.; SOUZA, C. F. Hidrogel como alternativa no aumento da capacidade de armazenamento de água no solo. Water Resources and Irrigation Management, Cruz das Almas, v. 2, n. 2, p: 87-92, 2013.

MENEZES, N. L.; ESPINDOLA, M. C. G.; PASQUALLI, L. L.; SANTOS, C. M. R.; FRANZIN, S. M. Associação de tratamentos pré-germinativos em sementes de Alface. Revista da Faculdade de Zootecnia, Veterinária e Agronomia, Uruguaiana, v. 13, n. 1, p: 1-11, 2006.

PACHECO, M. V.; MATOS, V. P.; FERREIRA, R. L. C.; FELICIANO, A. L. P.; PINTO, K. M. S Efeito de temperaturas e substratos na germinação de sementes de Myracrodruon urundevuva Fr. All. (ANACARDIACEAE). Revista Árvore, Viçosa, v. 30, n. 3, p: 359-367, 2006.

SANTI, A.; CARVALHO, M. A. C.; CAMPOS, O. R.; SILVA, A. F.; ALMEIDA, J. L.; MONTEIRO, S. Ação de material orgânico sobre a produção e características comerciais de cultivares de alface. Horticultura Brasileira, v. 28, n. 1, p: 87-90, 2010.

SILVA, H. P.; NEVES, J. M. G.; BRANDÃO JÚNIOR, D. S.; COSTA, C. A. Quantidade de água do substrato na germinação e vigor de sementes de Pinhão-manso. Revista Caatinga, Mossoró, v. 21, n. 5, p. 178-184, 2008.

VALE, G. F. R.; CARVALHO, S. P.; PAIVA, L. C. Avaliação da deficiência de polímeros hidroredentores no desenvolvimento do cafeeiro em pós-plantio. Coffee Science, Lavras, v. 1, n. 1, p. 7-13, 2006

VICENTE, M. R.; MENDES, A. A.; SAILVA, N. F.; OLIVEIRA, F. R.; MOTTA JÚNIOR, M. G.; LIMA, V. O. B. Uso de gel hidroretentor associado à irrigação no plantio do eucalipto. Revista Brasileira de Agricultura Irrigada, Fortaleza, v. 9, n. 5, p. 344-349, 2015.

TAIZ, L.; ZEIGER, E.; MOLLER, I. M.; MURPHY, A. Fisiologia e desenvolvimento vegetal. $6^{\mathrm{a}}$ ed. - Porto Alegre: Artmed, 2017. 